\title{
Decomposition of Sodium Tetraphenylborate
}

by

M. J. Barnes

Westinghouse Savannah River Company

Savannah River Site

Aiken, South Carolina 29808

DOE Contract No. DE-AC09-96SR18500

This paper was prepared in connection with work done under the above contract number with the U. S.

Department of Energy. By acceptance of this paper, the publisher and/or recipient acknowledges the U.S. Government's right to retain a nonexclusive, royalty-free license in and to any copyright covering this paper, along with the right to reproduce and to authorize others to reproduce all or part of the copyrighted paper. 


\section{DISCLAMMER}

This report was prepared as an account of work sponsored by an agency of the United States Government. Neither the United States Government nor any agency thereof, nor any of their employees, makes any warranty, express or implied, or assumes any legal liability or responsibility for the accuracy, completeness, or usefulness of any information, apparatus, product, or process disclosed, or represents that its use would not infringe privately owned rights. Reference herein to any specific commercial product, process, or service by trade name, trademark, manufacturer, or otherwise does not necessarily constitute or imply its endorsement, recommendation, or favoring by the United States Government or any agency thereof. The views and opinions of authors expressed herein do not necessarily state or reflect those of the United States Government or any agency thereof.

This report has been reproduced directly from the best available copy.

Available to DOE and DOE contractors from the Office of Scientific and Technical Information, P.O. Box 62, Oak Ridge, TN 37831; prices available from (615) 576-8401.

Available to the public from the National Technical Information Service, U.S. Department of Commerce, 5285 Port Royal Road, Springfield, VA 22161. 


\section{DISCLAIMER}

Portions of this document may be illegible in electronic image products. Images are produced from the best available original document. 


\title{
INFORMATION ONLY
}

WESTINGHOUSE SAVANNAH RIVER COMPANY SAVANNAH RIVER IAABORATORY

WSRC-RP $-90-465$

Keywords: In-tank process

Retention time: permanent

May 10, 1990

TO: D. L. FISH, 773-A

FROM: M. J. BARNES M

DO RETUAN IO SRL REEOREST, 773A

\author{
Decomposition of Sodium Tetraphenylborate (V)
}

\section{SUMMARY}

The chemical decomposition of aqueous alkallne solutions of sodium tetraphenylborate (NaTPB) has been investigated. The focus of the investigation is on the determination of additives and/or

variables which influence NaTPB decomposition. Copper(II) ions, solution temperature, and solution $\mathrm{pH}$ (hydroxide ion

concentration) have all been demonstrated to affect NaTPB

stability. Their relationship with each other and the stability

of NaTPB is presented. In additional work, the elimination of

oxygen from the reaction environment did not prevent NaTPB

decomposition in the presence of copper(II) ions, but did, however, affect the course of decomposition.

\section{INTRODUCTION}

NaTPB is a specialty chemical required for the In Tank Precipitation Process (ITP) 1,2 It precipitates cesium, aiding in the decontamination of high level radioactive waste solutions. It is to be obtained as an aqueous solution having a composition of $0.55 \pm 0.05 \mathrm{M}$ NaTPB and $0.10 \mathrm{M} \mathrm{NaOH}{ }^{3}$ of serlous concern, however, was the observation that upon production, the NaTPB showed varying degrees of stability. $4,5,6$ This led to an investigation into the causes and prevention of NaTPB decomposition.

Decomposition of NaTPB can occur in acidic solutions through acld hydrolysis. 7 In strongly basic solutions, NaTPB is generally considered to be quite stable. 8 However, certain components or conditions were found to be capable of decomposing NaTPB under basic conditions. These include copper(II), light, and temperature. Similarly, several components were previously tested and found to be inert to NaTPB (Appendix A). One particular additive, hydrogen peroxide, was determined to react 
stoichiometrically with tetraphenylborate (TPB-) but did not catalytically decompose TPB-. This document describes work aimed at providing 2 better understanding into the relationship of copper(II), solution temperature, and solution $\mathrm{pH}$ to NaTPB stability.

\section{DISCOSSION}

\section{Experimental Method and Details}

The method employed for decomposition testing of NaTPB solutions was incubation under controlled conditions. This was achieved by introducing additives into aqueous alkaline solutions of NaTPB and subjecting the NaTPB solutions to controlled environmental conditions (eg. temperature and/or nitrogen atmosphere). Long term exposures (over 30 weeks in some cases) were conducted to adequately determine the effect of the variables on the NaTPB solution's stability. Solutions were prepared from solid NaTPB. A.C.S. reagent grade NaTPB solid was purchased from the Aldrich Chemical Company with a purity greater than $99.5 \%$.

Typical test solutions studied were $25 \mathrm{~mL}$ in volume with compositions of approximately $0.5 \mathrm{M}$ NaTPB and $0.10 \mathrm{M} \mathrm{NaOH}$. Components were added to the test solutions using microliter pipettes and prepared stock solutions. All test solutions, unless otherwise stated, were stored at a temperature of $65^{\circ} \mathrm{C}$ in a laboratory oven in the presence of oxygen. The test solutions were stored in capped polyethylene bottles, except for those used in inert atmosphere studies. Inert atmosphere studies were conducted by preparing and capping the test solutions in serum glass vials inside a nitrogen filled glove bag.

Three methods were utilized to monitor TPB decomposition. These were silver ion titration, $\mathrm{pH}$, and visual observation. Samples were analyzed for TPB concentration either weekly or biweekly using a TPB-silver ion titration method. 9 Titration analyses of solutions approaching complete decomposition often ylelded unreasonable and inaccurate results. One probable source of error could be the over-titration of solutions containing little or no $\mathrm{TPB}^{-}$. A second source of error could occur if air bubbles were introduced into the titration apparatus tubing. Both would result in excessively high $\mathrm{TPB}^{-}$concentrations. Due to this problem, complete decomposition of $\mathrm{TPB}^{-}$was typically verified by spot testing the NaTPB solutions with potassium chloride. Exposure of potassium ions $\left(\mathrm{K}^{+}\right)$to TBP ${ }^{-}$ions results in formation of a white precipitate. Thus the spot test method provides a simple and accurate way of determining if any TPB is still present in the test solutions.

Measurement of the solution $\mathrm{pH}$ was found to be another method of monitoring NaTPB-solution stability. A drop in the $\mathrm{pH}$ was observed immediately prior to decomposition. NaTPB-solution pH was measured using a pH meter equipped with a gel-filled combination $\mathrm{pH}$ electrode. 
The solution appearance was also indicative of the stability of the solutions. Stable aqueous NaTPB solutions are a transparent, flesh-toned calor. During the initial stages of decomposition for instability), the solution turns a golden color. As the quantity of TPB that has decomposed increases, the solution turns dark red, then brown, and eventually black. Thus the stability of a solution can be easily estimated. Some exceptions were found. There were a few cases in which the solution's appearance indicated that decomposition had occurred, yet the TPB titration results and the other analyses proved otherwise.

\section{Results}

Three principal factors which affect the stability of NaTPB have been identified. These are 1) copper(II) ions, 2) temperature, and 3) solution $\mathrm{pH}$ (hydroxide ion concentration). Although ali three were previously determined to affect stability, knowledge of their relationship with each other was unclear. The experiments described herein were undertaken to gain an understanding of this relationship. The effects of three other potential contaminants were also examined. Two of these, magnesium (II) and lead (II), were selected because they might be present, in some form, in the ITP process scheme. The other, chromium (VI), was selected based upon its relatively hlgh degree of reactivity. None of these were found to affect NaTPB stability.

\section{iffect of copper}

Normal NaTPB solutions $(0.5 \mathrm{M}$ NaTPB and $0.1 \mathrm{M} \mathrm{OH})$, at $65^{\circ} \mathrm{C}$, are relatively stable over a long period of time. However, the addition of $10 \mathrm{ppm} \mathrm{Cu}$ (II) ions to this solution results in the decomposition of the NaTPB in less than three weeks. Experiments have shown that under these reaction conditions, initial Cu(II) concentrations of 0.1 to $100 \mathrm{ppm}$ will initiate decomposition. Lower $\mathrm{Cu}$ (II) concentrations may also result in decomposition given enough time. A NaTPB solution, with a $0.05 \mathrm{ppm} \mathrm{Cu(II)}$ concentration, began to show initial signs of decomposition in about 12 weeks. A drop in solution $\mathrm{pH}$ along with a gradual change in solution color was observed. After 25 weeks, the solution pH had dropped to 10.5 and the solution color was black, however, the NaTPB concentration remained near 0.5 molar.

Solutions containing larger concentrations of $\mathrm{Cu}$ (II) ions have an increased rate of decomposition. This is shown by the results listed in Table $I$ and can be seen graphically in Figure 1 . One anomaly observed in this data is that the solution containing the largest $\mathrm{Cu}$ (II) concentration (100 ppm) decomposed at a slightly slower rate than the $10 \mathrm{ppm} \mathrm{Cu}$ (II) solutions. This can best be explained by the observation that within the $100 \mathrm{ppm}$ test

solution, a substantial portion of the Cu(II) precipitates out of solution. This leaves a smaller concentration of Cu(II) remaining in solution, whereas the $10 \mathrm{ppm} C u$ (II) solution remains supersaturated and no precipitation occurs. Consequently, the $10 \mathrm{ppm} C u(I I)$ solution ultimately results in a larger Cu(II) 
concentration in solution. The actual $\mathrm{Cu}$ (II)-ion concentration in solution is under investigation at the present time. Preliminary results indicate less than $0.5 \mathrm{ppm} C u(I I)$ remains in solution, independent of the initial concentration of Cu(II).

\section{Temperature Dependence}

The rate of copper-induced decomposition is temperature dependent. Solutions similar to those reported above, containing initial concentrations of $\mathrm{Cu}$ (II) ions of 0.1 to $100 \mathrm{ppm}$, failed to decompose in more than thirty weeks at room temperature $\left(23 \pm 2^{\circ} \mathrm{C}\right)$. Data are listed in Table II. It is interesting to note that only the $10 \mathrm{ppm} \mathrm{Cu(II)-containing} \mathrm{solution} \mathrm{has} \mathrm{shown} \mathrm{any}$ signs of instability. In that particular case, the solution has gradually turned a gold-brown color and the solution pH has dropped to 10.7. However, the NaTPB concentration has remained near 0.5 molar. A substantial portion of the $\mathrm{Cu}$ (II) precipitated out of the solutions containing larger concentrations of Cu(II) (30 and $100 \mathrm{ppm}$ ). Based upon this information, NaTPB solutions which contain $\mathrm{Cu}$ (II) would be expected to remain stable for at least 6 to 8 months at room temperature.

\section{Solution $p A$ Dependence}

There is a trend of stabilizing NaTPB solutions with larger concentrations of $\mathrm{OH}^{-}$. Observation of these and old NaTPB solutions indicates that the $\mathrm{TPB}^{-}$concentration may remain constant for several weeks and/or years before rapidly decomposing in a short period of time. This suggests an autocatalytic mechanism. Solution $\mathrm{pH}$ has proven to be a useful way of following the stability of TPB-. Careful monitoring of $\mathrm{Cu}$ (II)-containing test solutions reveals that the solution $\mathrm{pH}$ decreases from approximately 13.0 to 11.0 just prior to TPB decomposition. This is presented graphically in Figure 2 for tests at $65^{\circ} \mathrm{C}$ and in Figure 3 for tests at room temperature. This finding suggests a way of predicting impending decomposition.

NaTPB test solutions $(0.5 \mathrm{M})$ containing $\mathrm{OH}^{-}$concentrations ranging from 0 to $0.5 \mathrm{M}$ were tested at $65^{\circ} \mathrm{C}$ both with and without $\mathrm{Cu}$ (II) (10.0 ppm) to examine the significance of the solution $\mathrm{pH}$. stability data obtained on these test solutions are listed in Table III and are plotted in Figure 4. Solutions containing $\mathrm{Cu}$ (II) in conjunction with $\mathrm{OH}^{-}$concentrations of $0.01 \mathrm{M}$ or less decomposed completely and rapidly ( $\leq 6$ days). Similarly their counterparts without $\mathrm{Cu}$ (II) decomposed rapidiy (s 6 days), but failed to completely decompose as evidenced by potassium ion spot testing. Unfortunately, all of these lower $\mathrm{pH}$-non Cu(II)-containing solutions were unable to be titrated accurately thereafter. This made quantification of the extent of decomposition impossible. The NaTPB test solution containing $\mathrm{CU}$ (II) and 0.5 molar $\mathrm{OH}^{-}$took over 4 weeks to decompose. Use of large concentrations of hydroxide, such as $0.5 \mathrm{M}$, affects the TPBtitration method giving erratic results. 
The observation of delayed decomposition in solutions containing elevated $\mathrm{OH}^{-}$concentrations prompted further testing. The addition of excess $\mathrm{OH}^{-}$to a $\mathrm{Cu}$ (II)-induced decomposing solution produced a significant finding. In the experiment, a Cu(II)-containing NaTPB solution was determined to be on the verge of decomposition three days after its preparation. An aliquot of the solution was withdrawn at that time and placed in a separate container. Concentrated $\mathrm{NaOH}\langle a q\rangle$ was then added to the original decomposing solution to raise its pH back to 13.0 . The unadjusted aliquot proceeded to decompose over the next four days. The original solution, whlch had been $\mathrm{pH}$ adjusted, remained relatively stable for an additional six weeks. This observation suggests periodically increasing the $\mathrm{pH}$ may help to stabilize solutions which are determined to be susceptible to decomposition.

The decreased $\mathrm{OH}^{-}$concentration studies produced another interesting observation. A NaTPB solution containing $0.001 \mathrm{M} \mathrm{OH}^{-}$ along with $10 \mathrm{ppm} F e$ (III), in place of $\mathrm{Cu}$ (II), remained stable over an eight week time period. This result is in contrast to the rapid decomposition observed when both $\mathrm{Cu}$ (II) was the additive in the solution and when no additive was present in the solution. The reason for this difference in stability remains a mystery. Data representing the latter two experiments are contained in Table IV.

\section{Mechanistic Copper Hork}

Copper is an ideal additive to use in NaTPB decomposition studies. NaTPB solutions initially seemed to decompose at random. This made the system difficult to study. The discovery that $C u(I I)$ was a decomposition catalyst allowed other additives and components to be tested on more predictable NaTPB solutions. NaTPB could now be expected to decompose in a given amount of time. This predictability has allowed additional work, almed at understanding the decomposition mechanism, to be conducted.

One mechanistic theory associated with NaTPB decomposition is that Cu(II). might be producing an intermediate complex in situ which is capable of reacting with NaTPB. The intermediate might be more reactive with another compound than it would be with NaTPB if this were occurring. Decomposition of NaTPB could be prevented if this were true. Fe(III) was tested as an additive in confunction with CU(II)-containing NaTPB solutions based upon this idea and the previous observation of increased stability with an Fe(III) additive in low $\mathrm{OH}^{-}$solutions. Unfortunately, no NaTPB stabilization was gained in this experiment. In fact, NaTPB decomposed at a slightly enhanced rate. The presence of Cu(II) in this experiment determines the fate of the NaTEB and the Fe(III) has little affect on the stability process.

The idea of an intermediate being produced in situ, which could cause the decomposition of NaTPB, was further tested by adding a $5.0 \mathrm{~mL}$ aliquot of a previously decomposed NaTPB solution to an otherwise stable NaTPB solution. The $5.0 \mathrm{~mL}$ allquot was 
determined to contain enough $\mathrm{Cu}$ (II) to produce an approximately $0.03 \mathrm{ppm} C u(I I)$ resulting solution. No sign of decomposition occurred in eighteen weeks. This suggests that no intermedlate capable of initiating decomposition was present in the aliquot. Data representing the above cases are listed in Table $V$.

\section{Iffect of Oxygon}

Eliminating oxygen does not prevent the decomposition of NaTPB in the presence of $\mathrm{Cu}$ (II) ions. However, it does affect the course of the decomposition. This was observed in an experiment in which Cu(II)-containing NaTPB solutions were prepared in the absence of oxygen. It was thought that copper was reacting with oxygen to produce an intermediate complex which could decompose NaTPB. Therefore, if oxygen was removed from the solution environment, NaTPB decomposition could be prevented. In order to minimize the chance of exposing the test solutions to oxygen, TPB- titration analysis was conducted only when the solutions' daily appearance was observed to change. Unexpectedly, decomposition did occur. However, several properties assoclated with the decomposition were different from what normally is observed when decomposition occurs in the presence of oxygen. These differences are summarized in Table VI.

The most noticeable difference observed when comparing the two decomposed solutions was that no change in the solution color occurred during decomposition in the absence of oxygen. An organic layer formed on the surface of the aqueous solution along with the formation of a white crystalline precipitate. Titration analysis of the aqueous portion of the solution indicated that no $\mathrm{TPB}^{-}$was present. The $\mathrm{pH}$ of the aqueous portion was determined to be approximately 12. Analysis of the organic layer by liquid chromatography identified benzene as the primary component along with smaller amounts of biphenyl, terphenyl, and a few unidentified compounds. No phenol or phenylboronic acid was observed in the organic layer.

Comparatively, decomposition of NaTPB in the presence of oxygen results in the solption turning a dark brown-black color. No organic layer or precipitate is usually observed. The solution $\mathrm{pH}$ drops to approximately 11. Finally, phenol and phenylboronic acid are produced as well as benzene, biphenyl, and other benzene ring derivatives.

These differences in the two decomposition processes suggest that oxygen does not play a role in the initial steps of decomposition. However, it is involved in a secondary reaction with the intermediate complexes produced during the initial stages of decomposition.

\section{Magnesium (II), Chromium (VI), and Iead (II)}

The presence of $\mathrm{Mg}(I I), \mathrm{Pb}(I I)$, or $\mathrm{Cr}$ (VI) does not cause NaTPB to decompose. Normal NaTPB solutions $\left(0.5 \mathrm{M}\right.$ NaTPB and $\left.0.1 \mathrm{M} \mathrm{OH}^{-}\right)$ 
containing either $\mathrm{Mg}$ (II) or $\mathrm{Pb}$ (II) were tested at $65^{\circ} \mathrm{C}$. They remained relatively stable over an eight week period, as evidenced by their solution $\mathrm{PH}$ and $\mathrm{TPB}^{-}$titration data listed in Table VII. Similar test solutions containing $\mathrm{Cr}$ (VI) remained equally stable and are similarly reported in Table VII.

\section{CONCLUSIONS}

It has been shown that copper concentrations as 10 as $0.10 \mathrm{ppm}$ can result in the decomposition of NaTPB solutions at $65^{\circ} \mathrm{C}$. However, the NaTPB solutions appear to be stable for at least 6 to 8 months when held at room temperature $\left(23^{\circ} \mathrm{C}\right)$. The stability can be enhanced by the addition of hydroxide to the solution. Decomposition was not initiated or accelerated by the presence of intermediates generated in situ and is not prevented by the elimination of oxygen from the NaTPB solution environment. The decomposition mechanism is affected by the atmosphere under which it is stored. Both $\mathrm{pH}$ and visual appearance as well as silver $10 \mathrm{n}$ titration were found to be effective methods of monitoring the decomposition.

Additional decomposition studies at $40^{\circ} \mathrm{C}$ are underway. These should help provide an increased capability for predicting the stability of actual NaTPB solutions containing Cu(II) at temperatures above room temperature. This data will be documented in a later report.

\section{QUALITY ASSURANCE}

All work was conducted in accordance with the SRI Quality Assurance Program. Data are recorded in Laboratory Notebook WSRC-NB-89-11, pp. 3-84. Salt solutions were prepared from reagent grade chemicals. TRB titration analyses weire performed by the DWPT Analytical Laboratory at TNX. A sloped calibration of the pH meter was conducted prior to its use each day.

\section{REERREHCES}

1. L. M. Lee and I. I. Kilpatrick, "A Precipitation Process for Supernate Decontamination," DP-1636, November 1982.

2. D. D. Walker and M. A. Schmitz, "Technical Data Summary: InTank Precipitation Processing of Soluble High-Level Waste," DPSTD-84-103, MaY 1984.

3. J. A. Mieth, "In-Tank Precipitation Cold Chemical Quality Control Program," DPSP-89-17-21, September 13, 1989.

4. Business Correspondence, J. Singh of AFF inc. D. D. Walker, September 22, 1989.

5. Memorandum, D. D. Walker to M. J. Barnes, "NaTPB Stability," October 18, 1989. 
6. D. T. Hobbs, "Long Term Storage of Sodium Tetraphenylborate Solutions," DPST-88-1044, December 30,1988.

7. J. R. Fowler, "Acid Hydrolysis of Tetraphenylborate," DPST-83-1099, December 28, 1983.

8. S. S. Cooper, Analytical Chemistry, 29, 446, March 1957.

9. C. J. Coleman, "Determination of Tetraphenylborate in Precipitation Reactor Feed," DPST-88-277, 1988. 


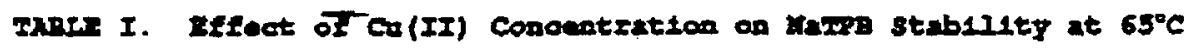

MaTPG-Solution Molarity and pH

\begin{tabular}{|c|c|c|c|c|c|c|c|c|c|c|c|c|}
\hline \multirow{2}{*}{$\begin{array}{c}\text { Time } \\
\text { (weths) }\end{array}$} & \multicolumn{2}{|c|}{$\begin{array}{c}0.00 \mathrm{ppm} \\
\text { Cu(ii) }\end{array}$} & \multicolumn{2}{|c|}{$\begin{array}{c}0.00 \text { ppm } \\
\text { Cu(t) }\end{array}$} & \multicolumn{2}{|c|}{$\begin{array}{c}0.00 \text { ppm } \\
\text { Cu(II) }\end{array}$} & \multicolumn{2}{|c|}{$\begin{array}{c}0.05 \text { ppm } \\
\text { cuph }\end{array}$} & \multicolumn{2}{|c|}{$\begin{array}{c}0.10 \text { ppm } \\
\text { cu(ii) }\end{array}$} & \multicolumn{2}{|c|}{$\begin{array}{c}0.10 \mathrm{ppm} \\
\text { Cu(i) }\end{array}$} \\
\hline & NATPE (Mil & DH & Nater ain & 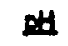 & UTTPA (N) & pH & NRTeP(in) & Det & NATPE (Mil & $\mathrm{DH}$ & Nates im & ats \\
\hline 1 & 0.50 & - & 0.50 & -. & 0.50 & 12.9 & 0.45 & 12.9 & 0.50 & -- & 0.49 & 12.8 \\
\hline 2 & 0.48 & -. & 0.51 & ـ & 0.51 & 12.8 & -. & - & 0.48 & .. & -- & $\cdots$ \\
\hline 3 & 0.50 & 12.8 & 0.50 & 13.0 & 0.52 & 12.8 & - & - & 0.49 & 13.0 & - & -- \\
\hline 4 & 0.50 & 12.8 & 0.51 & 12.8 & 0.54 & 12.8 & 0.49 & 12.8 & 0.49 & 12.8 & - & 12.8 \\
\hline 5 & - & .- & - & .. & -• & - & - & - & 0.50 & 13.t & 0.53 & - \\
\hline 6 & 0.56 & 12.7 & 0.57 & 12.7 & $\bullet$ & 12.5 & - & . & - & 10.7 & - & $\cdots$ \\
\hline 7 & - & - & - & - & 0.59 & 12.9 & - & .. & $*$ & . & - & $\therefore$ \\
\hline 8 & 0.62 & 12.7 & 0.62 & 12.7 & 0.64 & 12.7 & 0.50 & - & 0.59 & 10.7 & 0.47 & $\cdots$ \\
\hline 9 & & & & & & & $\because-$ & - & & & 0.16 & 11.0 \\
\hline 10 & & & & & & & -- & 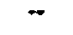 & & & $<0.01$ & 10.7 \\
\hline 11 & & & & & & & - & - & & & & \\
\hline 12 & & & & & & & 0.51 & 12.7 & & & & \\
\hline 15 & & & ' & & & & 0.53 & 12.4 & & & & \\
\hline 17 & & & & & & & 0.51 & 11.3 & & & & \\
\hline 18 & & & & & & & - & 10.9 & & & & \\
\hline 19 & & & & & & & 0.47 & 10.9 & & & & \\
\hline 22 & & & & & & & 0.49 & 10.4 & & & & \\
\hline 25 & & & & & & & - & 10.5 & & & & \\
\hline
\end{tabular}

TABLF I. (contianed from sbove)

NoTPE-Solutton Molerity and $\mathrm{PH}$

\begin{tabular}{|c|c|c|c|c|c|c|c|c|c|c|c|c|}
\hline \multirow{2}{*}{$\begin{array}{c}\text { Time } \\
\text { (weskst) }\end{array}$} & \multicolumn{2}{|c|}{$\begin{array}{c}0.50 \mathrm{ppm} \\
\text { Cu(ti) }\end{array}$} & \multicolumn{2}{|c|}{$\begin{array}{c}1.00 \text { ppm } \\
\text { Cu(ii) }\end{array}$} & \multicolumn{2}{|c|}{$\begin{array}{l}\text { 10. ppm } \\
\text { Cu(t) }\end{array}$} & \multicolumn{2}{|c|}{$\begin{array}{c}\text { 10. Ppm } \\
\text { Cu(II) }\end{array}$} & \multicolumn{2}{|c|}{$\begin{array}{l}\text { 30. Ppm } \\
\text { cu(i) }\end{array}$} & \multicolumn{2}{|c|}{$\begin{array}{l}\text { 100. ppm } \\
\text { Cu(II) }\end{array}$} \\
\hline & NatPe (nin & ot & NATPe_aid & Det & NeIPQ (M) & ad & NeTPE (M) & 면 & NetPe (Mi) & pHit & NoTPQ (M) & DH \\
\hline ? & -- & - & -. & r & -- & .- & 0.49 & 12.9 & 0.46 & -- & 0.47 & .. \\
\hline 2 & -- & $\infty$ & - & .- & .. & - & 0.49 & 12.5 & - & - & 0.46 & - \\
\hline 3 & $m$ & 10.9 & $<0.01$ & 10.8 & $<0.01$ & 11.0 & $<0.01$ & 10.9 & $<0.01$ & 11.1 & - & 13.0 \\
\hline 4 & 0.46 & 90.7 & & & & & & & & & $<0.01$ & 10.8 \\
\hline 5 & $<0.01$ & -- & & & & & " & & & & & . \\
\hline
\end{tabular}

All solutions containing $0.50 \mathrm{ppm}$ "Cu(II) or greater decomposed in 5 weeks or less. 
TABIE II. Iffect of Cu(II) Concentration on NaTPB

Stability at Room Temperature

NaTPB-Solution Molarity and pH

Time

$$
0.00 \mathrm{ppm}
$$

$0.00 \mathrm{ppm}$

DH CuTP(ii)

$0.10 \mathrm{ppm}$

DH Natpe(M)

$0.50 \mathrm{ppm}$

Cu(II)

Cu(II)

(wooks) NaTPB (M) DH NaTPB (M) DH NaTPB (M) dH NaTPB (M) eH

\begin{tabular}{|c|c|c|c|c|c|c|c|c|}
\hline 1 & 0.48 & -. & 0.46 & .. & 0.48 & -. & 0.45 & $\cdots$ \\
\hline 2 & .. & . & 0.46 & - & 0.49 & .. & 0.47 & .. \\
\hline 3 & 0.50 & 12.8 & 0.47 & 13.0 & 0.47 & 13.2 & 0.46 & 13.2 \\
\hline 4 & 0.48 & 12.9 & 0.48 & 12.8 & 0.48 & 12.9 & 0.47 & 12.8 \\
\hline 6 & 0.48 & 12.7 & 0.48 & 12.6 & 0.47 & 12.8 & 0.47 & 12.7 \\
\hline 8 & 0.48 & 12.6 & 0.48 & 12.6 & 0.49 & 12.7 & 0.48 & 12.6 \\
\hline 16 & 0.51 & 12.9 & 0.47 & 12.9 & 0.53 & 12.9 & 0.48 & 12.9 \\
\hline 19 & - & - & -- & -. & .. & -. & -- & -. \\
\hline 21 & -- & $\cdots$ & 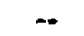 & -- & .. & .. & -- & -- \\
\hline 22 & - & 12.9 & -. & 12.9 & $\therefore$ & 12.8 & $\cdots$ & 12.8 \\
\hline 25 & 0.49 & 12.9 & 0.49 & 12.9 & 0.49 & 12.8 & 0.46 & 12.8 \\
\hline 28 & -- & & .. & -. & .- & -. & .. & .. \\
\hline 30 & -. & & -. & $\cdots$ & -. & -- & $\cdots$ & .. \\
\hline 32 & $\cdots$ & 12.7 & $\cdots$ & 12.8 & -. & 12.8 & $\ldots$ & 12.6 \\
\hline
\end{tabular}

TABLE II. (continued from above)

NaTPB-Solution Molarity and pH

Time

$1.00 \mathrm{ppm}$

10. ppm

Cu(It)

30. ppm

Cu(II)

100. $\mathrm{ppm}$

Cu(II)

(weaks) NaTPE(M) aH NaTPB (M) aH NaTPB (M) aH NaTPB(M) aH

\begin{tabular}{|c|c|c|c|c|c|c|c|c|}
\hline 1 & 0.44 & .. & 0.48 & .- & 0.48 & -. & 0.44 & -. \\
\hline 2 & 0.45 & .. & -- & .. & 0.47 & -- & 0.46 & -- \\
\hline 3 & 0.46 & 13.2 & 0.47 & 13.2 & 0.47 & 13.2 & 0.46 & 13.2 \\
\hline 4 & 0.46 & 12.8 & 0.48 & 12.8 & 0.48 & 12.8 & 0.47 & 12.8 \\
\hline 6 & 0.46 & 12.7 & 0.48 & 12.7 & 0.48 & 12.7 & 0.46 & 12.8 \\
\hline 8 & 0.47 & 12.6 & 0.48 & .12 .6 & 0.47 & 12.6 & 0.46 & 12.6 \\
\hline 16 & 0.47 & 12.8 & 0.48 & 12.6 & 0.51 & 12.8 & 0.45 & 12.8 \\
\hline 19 & $\cdots$ & $\cdots$ & 0.44 & 12.4 & -- & -. & .. & -- \\
\hline 21 & -. & -- & 0.45 & 12.2 & -- & -. & -- & -. \\
\hline 22 & 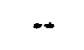 & 12.7 & 0.45 & 12.1 & -- & 12.7 & $\cdots$ & 12.8 \\
\hline 25 & 0.45 & 12.6 & 0.46 & 11.9 & 0.47 & 12.7 & 0.47 & 12.7 \\
\hline 28 & - & 12.6 & 0.52 & 11.3 & $\cdots$ & 12.7 & - & 12.7 \\
\hline 30 & -. & .. & 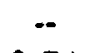 & 10.7 & -- & -- & .. & 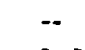 \\
\hline 32 & .. & 12.3 & 0.51 & 10.7 & .. & 12.5 & .. & 12.6 \\
\hline
\end{tabular}


TABII III. Efsect of Eydroxido Concentration on NaTPB stability at $65^{\circ} \mathrm{C}$

NaIPE-Solution Molarity and oH

\begin{tabular}{|c|c|c|c|c|c|c|c|c|c|c|}
\hline \multirow{3}{*}{$\begin{array}{c}\text { Time } \\
\text { (weeks) }\end{array}$} & \multirow{2}{*}{\multicolumn{2}{|c|}{$\begin{array}{c}\text { 0.5 MNAOH } \\
\text { 10. ppm } \\
\text { Cu(II) }\end{array}$}} & \multicolumn{4}{|c|}{$0.10 \mathrm{M} \mathrm{NaOH}$} & \multicolumn{4}{|c|}{$0.01 \mathrm{M}$ NaOH } \\
\hline & & & \multicolumn{2}{|c|}{$\begin{array}{c}0.00 \mathrm{ppm} \\
\text { Cu(II) }\end{array}$} & \multicolumn{2}{|c|}{$\begin{array}{l}\text { 10. ppm } \\
\text { Cu(ii) }\end{array}$} & \multicolumn{2}{|c|}{$\begin{array}{c}0.00 \mathrm{ppm} \\
\text { cu(II) }\end{array}$} & \multicolumn{2}{|c|}{$\begin{array}{l}\text { 10. ppm } \\
\text { Cu(Ji) }\end{array}$} \\
\hline & NaIPB (M) & 애 & NeTPB (M) & DH & NATPB (M) & pH & NaTPB (M) & ptid & $\operatorname{NaTPB}(M)$ & 매 \\
\hline 1 & 0.32 & 13.4 & 0.50 & 13.4 & 0.48 & 13.2 & 0.48 & 11.0 & $<0.01$ & 10.9 \\
\hline 2 & 0.48 & 13.4 & 0.51 & 12.8 & 0.49 & 12.5 & 0.48 & 10.2 & & \\
\hline 3 & -. & 12.9 & 0.52 & 12.8 & $<0.01$ & 10.9 & 0.50 & -. & & \\
\hline 4 & .. & 12.7 & 0.54 & 12,8 & & & 0.40 & 10.1 & & \\
\hline 6 & $<0.01$ & -- & -- & 12.5 & & & 0.39 & 10.1 & & \\
\hline 7 & & & 0.59 & 12.9 & & & 0.39 & .. & & \\
\hline 8 & & & 0.64 & 12.7 & & & 0.39 & .. & & \\
\hline
\end{tabular}

TABIF III. (continued from above)

NatPB-Solukion Malarity and $\mathrm{nH}$

\begin{tabular}{|c|c|c|c|c|c|c|c|c|c|c|}
\hline \multirow{3}{*}{$\begin{array}{c}\text { Time } \\
\text { (wenks) }\end{array}$} & \multicolumn{4}{|c|}{$0.001 \mathrm{MNaOH}$} & \multicolumn{2}{|c|}{$0.0001 \mathrm{M} \mathrm{NaOH}$} & \multicolumn{4}{|c|}{$\mathrm{NoNaOH}$} \\
\hline & \multicolumn{2}{|c|}{$\begin{array}{c}0.00 \mathrm{ppm} \\
\text { Cu(it) }\end{array}$} & \multicolumn{2}{|c|}{$\begin{array}{l}\text { 10. ppm } \\
\text { cu(ii) }\end{array}$} & \multicolumn{2}{|c|}{$\begin{array}{c}0.00 \mathrm{ppm} \\
\mathrm{Cu}(1 i)\end{array}$} & \multicolumn{2}{|c|}{$\begin{array}{c}0.00 \mathrm{ppm} \\
\mathrm{Cu}(\mathrm{II})\end{array}$} & \multicolumn{2}{|c|}{$\begin{array}{l}\text { 10. ppm } \\
\text { Cu(II) }\end{array}$} \\
\hline & NaTPB $(M)$ & DH & NaTPR (M) & pH & NATPE (M) & pH & NaTPE $(M)$ & DH & NaTPQ (M) & $\mathrm{pH}$ \\
\hline 1 & $\mathrm{NCO}$ & 10.8 & $<0.01$ & 10.9 & $1 \times 0$ & 10.8 & NOD & 10.7 & $<0.01$ & 10.9 \\
\hline 2 & & & & & & & & & & \\
\hline 3 & & & & & & & & & & \\
\hline 4 & & & & & & & & & & \\
\hline 6 & & & & & & & & & & \\
\hline 7 & & & & & & & & & & \\
\hline 8 & & & & & & & & & & \\
\hline
\end{tabular}

INCD indicates the NaTPB solution has not completely decomposed but also not able to be titrzted. 
TABIE IV. Mechanistic pH studieg at $65^{\circ} \mathrm{C}$

NaTPG-Solution Molarity and PH

\begin{tabular}{|c|c|c|c|c|c|c|c|}
\hline \multirow{3}{*}{\multicolumn{2}{|c|}{ Ilme (weeks) }} & \multicolumn{4}{|c|}{$\begin{array}{l}\text { NaTPB solution contalning } \\
10 \mathrm{ppm} \text { Cu(iI) divided } \\
\text { Into two portions on day } 3\end{array}$} & \multirow{2}{*}{\multicolumn{2}{|c|}{$\begin{array}{c}0.0001 \mathrm{M} \mathrm{NaOH} \\
\text { 10. ppm } \\
\text { Fe(III) }\end{array}$}} \\
\hline & & \multicolumn{2}{|c|}{$\begin{array}{r}\text { Excess } \mathrm{NaOH} \\
\text { added on day } 3\end{array}$} & \multicolumn{2}{|c|}{$\begin{array}{c}\text { No } \mathrm{NaOH} \\
\text { added on day } 3\end{array}$} & & \\
\hline & & NaTEB (Mi) & DH & NaTPE (M) & pH & NateB (M) & DH \\
\hline 1 & day 1 & - & 12.7 & -- & 12.7 & - & + \\
\hline & day 3 & -- & 12.3 & -- & 12.3 & $\cdots$ & -- \\
\hline & day 7 & - & 12.9 & $<0.01$ & 10.8 & 0.50 & 9.7 \\
\hline 2 & & -- & 12.8 & & & 0.46 & 9.6 \\
\hline 3 & & 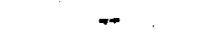 & - & & & -. & -. \\
\hline 4 & & 0.46 & 12.5 & & . & 0.46 & 9.9 \\
\hline 6 & & 0.49 & 12.6 & & $\cdot$ & 0.48 & 10.1 \\
\hline 7 & & $<0.01$ & 12.5 & & & - & -. \\
\hline 8 & & & & & & 0.49 & 10.3 \\
\hline
\end{tabular}


D. I. Fish

WSRC-RP-90-465

TABLE V. Mechanistic Copper Studies at $65^{\circ} \mathrm{C}$

NaTPB-Solution Molarity and pH

\begin{tabular}{|c|c|c|c|c|c|c|c|c|}
\hline \multirow{3}{*}{$\begin{array}{c}\text { Time } \\
\text { (reeks) }\end{array}$} & \multicolumn{6}{|c|}{$\begin{array}{l}\text { NaTPB solution containing 10. ppm Cu(II) } \\
\text { and the listed quentity of Fo(lli) }\end{array}$} & \multicolumn{2}{|c|}{$\begin{array}{l}25 \mathrm{~mL} \text { NaTPB solution } \\
\text { containing } 5 \mathrm{~mL} \text { of } \\
\text { decomposed } \\
\text { AFF sample \#267 }\end{array}$} \\
\hline & \multicolumn{2}{|c|}{$\begin{array}{l}\text { 10. Ppm } \\
\text { Fe(III) }\end{array}$} & \multicolumn{2}{|c|}{$\begin{array}{l}\text { 30. Ppm } \\
\text { Fo(III) }\end{array}$} & \multicolumn{2}{|c|}{$\begin{array}{l}\text { 100. Ppm } \\
\text { Fo(III) }\end{array}$} & \multicolumn{2}{|c|}{$\begin{array}{l}0.03 \text { ppm } \\
\text { Cu(Ui) }\end{array}$} \\
\hline & NaTPB (M) & 매 & NaTPB (M) & DH & NATPB (M) & nH & NaTPB (M) & $\mathrm{pH}$ \\
\hline 1 & - & -. & 0.28 & - & 0.46 & -- & 0.48 & 13.0 \\
\hline 2 & $<0.01$ & $\because$. & $<0.01$ & -. & $<0.01$ & - & -- & 13.1 \\
\hline 3 & & 11.1 & & 11.1 & & 11.1 & 0.48 & 13.1 \\
\hline 4 & & & & & & & 0.50 & 13.2 \\
\hline 6 & & & & & & & 0.54 & 13.1 \\
\hline 7 & & & & & & & -. & -- \\
\hline 9 & & & & & & & 0.57 & 13.0 \\
\hline 12 & & & & & & & 0.53 & 13.0 \\
\hline 15 & & & & & & & 0.48 & 12.8 \\
\hline 18 & & & & & & & -. & 12.7 \\
\hline
\end{tabular}

${ }^{3} \mathrm{Cu}(\mathrm{II})$ concentration in the solution is based on the measured copper concentration of AFF sample \#267. 
Table VI. NaTPB Solution Differences Between Air and Nitrogen Decomposition Processes

\section{Characteristic}

Color

Organic phase

Precipitate

Solution ph

Products

\section{Presence}

ef exycon

brown-black

no

no

drops to 11

benzene

phenol

phenylboronic acid

biphenyl

others

\author{
Absence \\ of oxroten \\ clear \\ yes \\ yes \\ drops to 12 \\ benzene \\ biphenyl \\ terpheny 1 \\ others
}


TRBII FI. Fffect of Additional Additives

on NaTPB-Solution Stability at $65^{\circ} \mathrm{C}$

NaTPB_Solution Molarity and pH

\begin{tabular}{|c|c|c|c|c|c|c|}
\hline \multirow{2}{*}{$\begin{array}{c}\text { TIme } \\
\text { (reeks) }\end{array}$} & \multicolumn{2}{|c|}{$\begin{array}{l}\text { 10. ppm } \\
\mathrm{Mg}(\mathrm{II})\end{array}$} & \multicolumn{2}{|l|}{$\begin{array}{l}\text { 30. Ppm } \\
\text { Mg(II) }\end{array}$} & \multicolumn{2}{|l|}{$\begin{array}{l}\text { 100. ppm } \\
\text { Mg(II) }\end{array}$} \\
\hline & NaTPB (Mi) & DH & NaTPB (MI) & $\mathrm{pH}$ & NaTeg (M) & DH \\
\hline 1 & 0.54 & 12.9 & 0.52 & 12.6 & 0.49 & 12.4 \\
\hline 2 & 0.51 & 12.6 & 0.51 & 12.7 & 0.50 & 12.3 \\
\hline 3 & -. & .. & .. & .. & .. & .. \\
\hline 4 & 0.53 & 12.5 & 0.53 & 12.2 & 0.52 & 12.1 \\
\hline 6 & 0.57 & 12.7 & 0.55 & 12.5 & 0.53 & 12.5 \\
\hline 8 & 0.58 & 12.7 & 0.58 & 12.7 & 0.56 & 12.6 \\
\hline
\end{tabular}

NaTPB-Solution Molarity and pH

Time

(weeks)

$$
\begin{aligned}
& 1 \\
& 2 \\
& 3 \\
& 4 \\
& 6 \\
& 8
\end{aligned}
$$

Time

\section{(reeks)}

1
2
3
4
6
8

10. ppm

Cr(VI)

NaTPE (M) DH

$\begin{array}{cc}0.48 & - \\ 0.50 & - \\ 0.49 & 13.2 \\ 0.51 & 12.9 \\ 0.57 & 12.9 \\ 0.60 & 12.7\end{array}$

30. ppm

Cr(VI)

NaTPe (M) at

0.46

0.50

0.49

0.51

0.55

0.60

.-
13.2
13.9
12.8
12.6

100. ppm

$\mathrm{Cr}(\mathrm{VI})$

NaTPE (M) DH

0.48

\begin{tabular}{|c|c|c|c|c|c|}
\hline \multicolumn{2}{|l|}{$\begin{array}{c}\text { 10. ppm } \\
\mathrm{Pb}(\mathrm{II})\end{array}$} & \multicolumn{2}{|l|}{$\begin{array}{l}\text { 30. ppm } \\
\text { Pb(II) }\end{array}$} & \multicolumn{2}{|c|}{$\begin{array}{l}\text { 100. ppm } \\
\text { Pb(II) }\end{array}$} \\
\hline NeTPE (M) & pH & NaTPB (Mi) & pH & NaTPE (M) & pH \\
\hline 0.50 & -- & 0.49 & .. & 0.48 & $\ldots$ \\
\hline 0.51 & 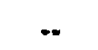 & 0.51 & -- & 0.46 & - \\
\hline 0.49 & 13.1 & 0.49 & 13.1 & .. & 13.2 \\
\hline 0.51 & 12.8 & 0.52 & 12.8 & 0.49 & 12.8 \\
\hline 0.57 & 12.8 & 0.55 & 12.7 & 0.55 & 12.8 \\
\hline 0.59 & 12.7 & 0.59 & 12.7 & 0.60 & 12.7 \\
\hline
\end{tabular}

0.49

..

$0.54 \quad 12.7$

$0.57 \quad 12.7$

NaTPB-Solution Molarity and pH 
Figure 1. Effect of Copper Concentration on Narra-
Solution stability at $65^{\circ} \mathrm{C}$

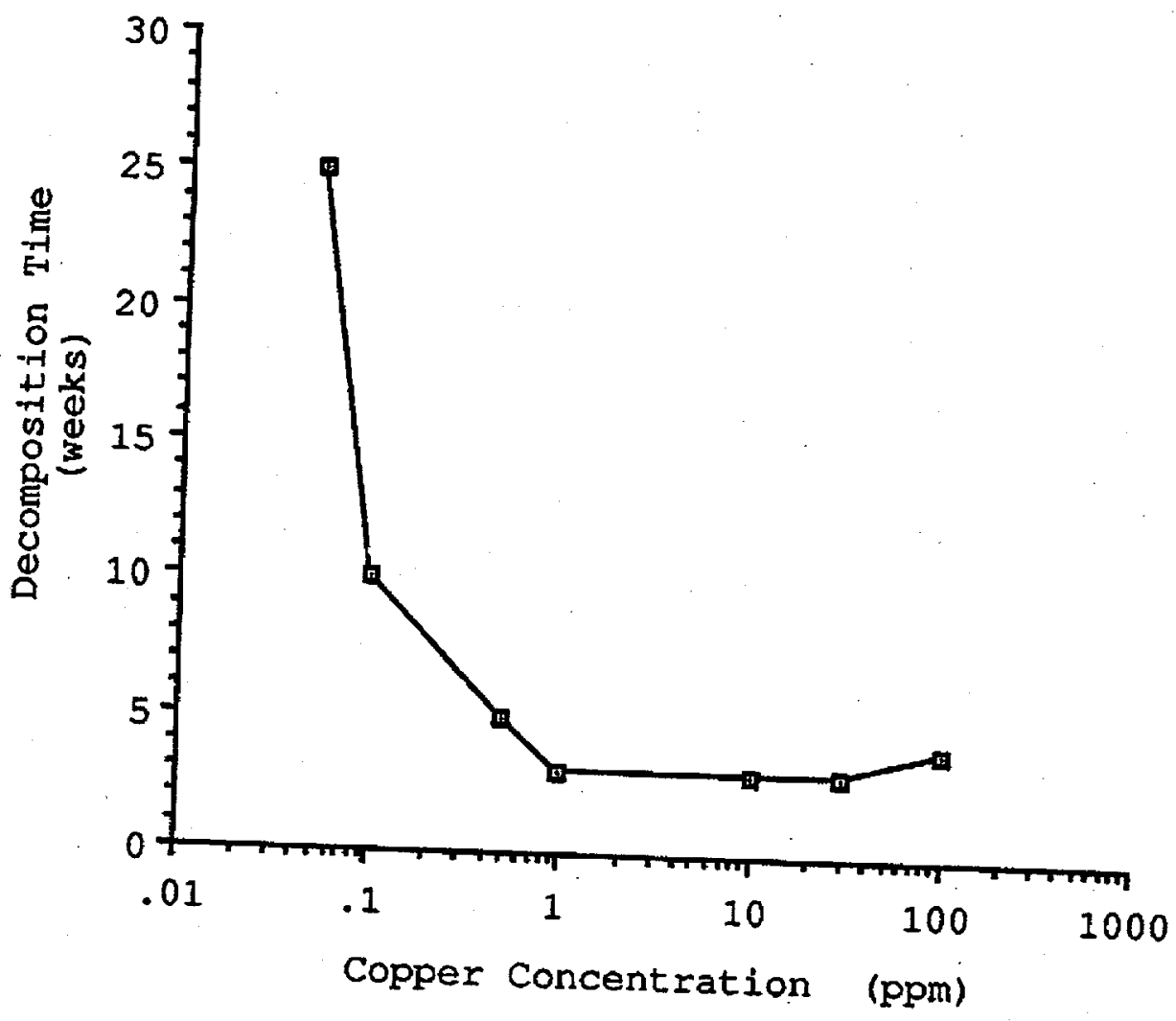


D. I. Fish

Figure 2. Solution pH va. Time for NaTPB Solutions with and without copper at $65^{\circ} \mathrm{C}$

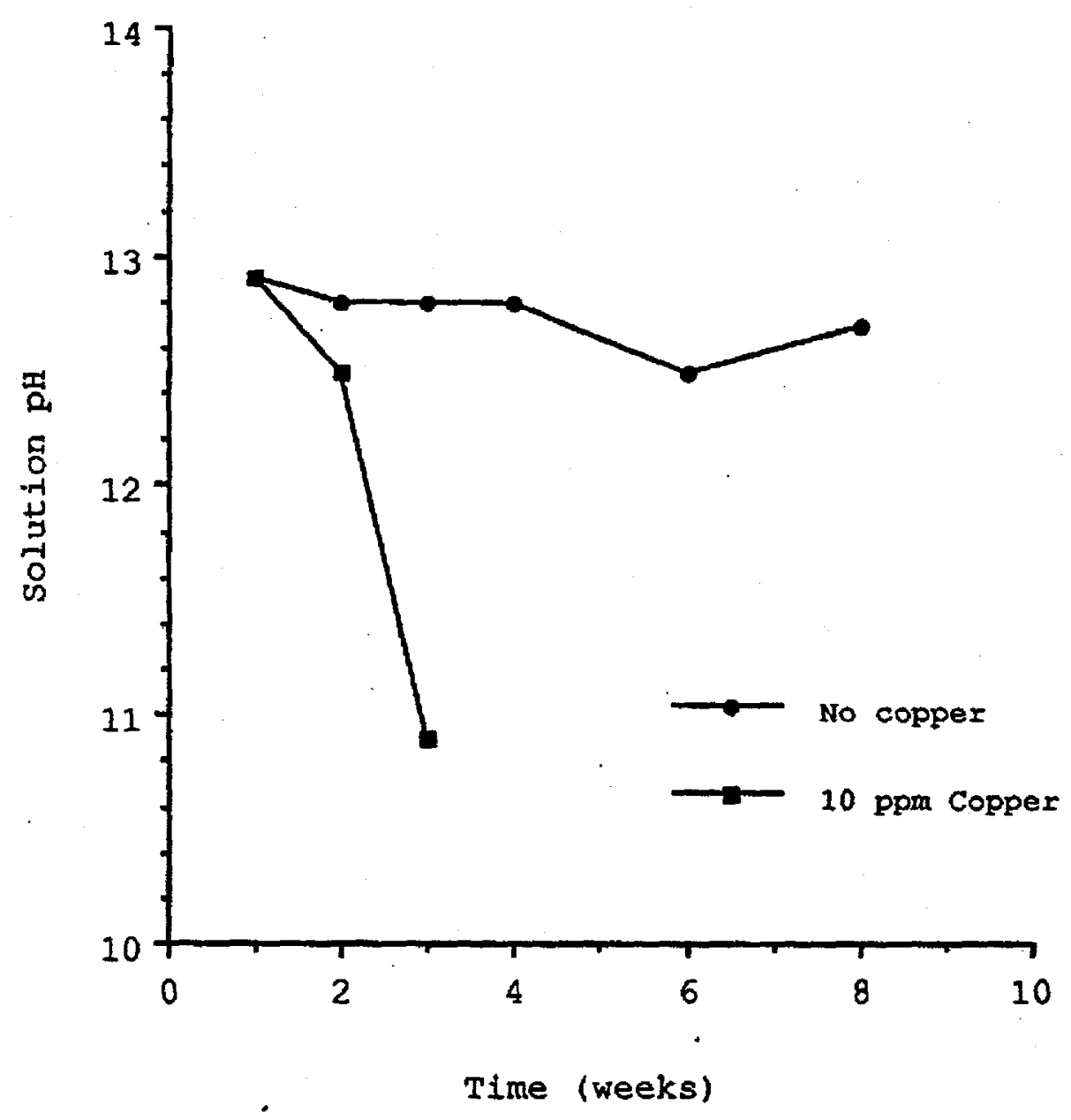



D. I. Fish

\section{Figure 3. Solution $\mathrm{pH}$ vs. Time for a 10 ppm Copper-
Containing NarpB Solution at Room Temperature}

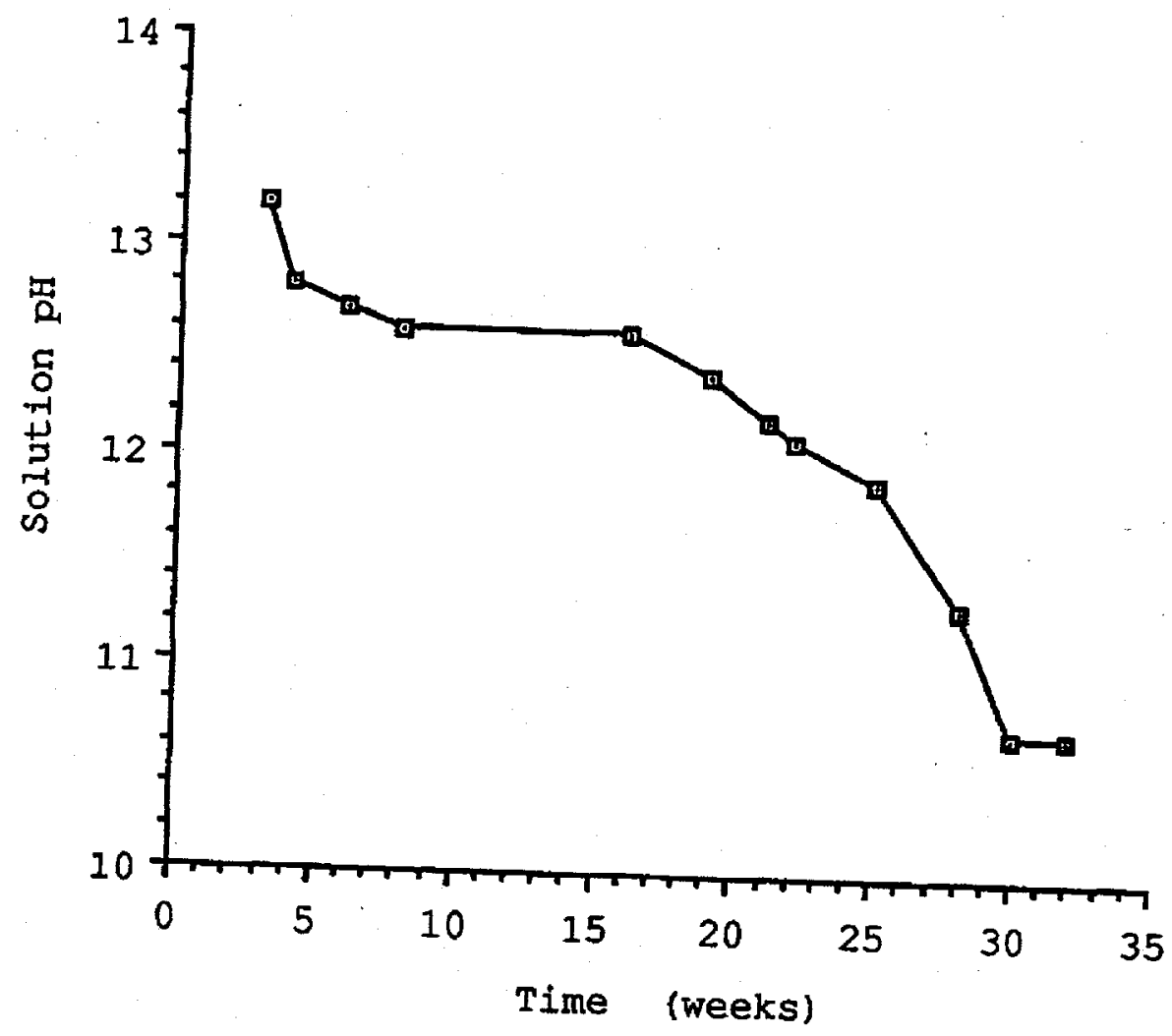


Figure 4. Decomposition Time of Copper-Containing Namp
Solutions with Varying Hydroxide Ion
Concentrations at $65^{\circ} \mathrm{C}$

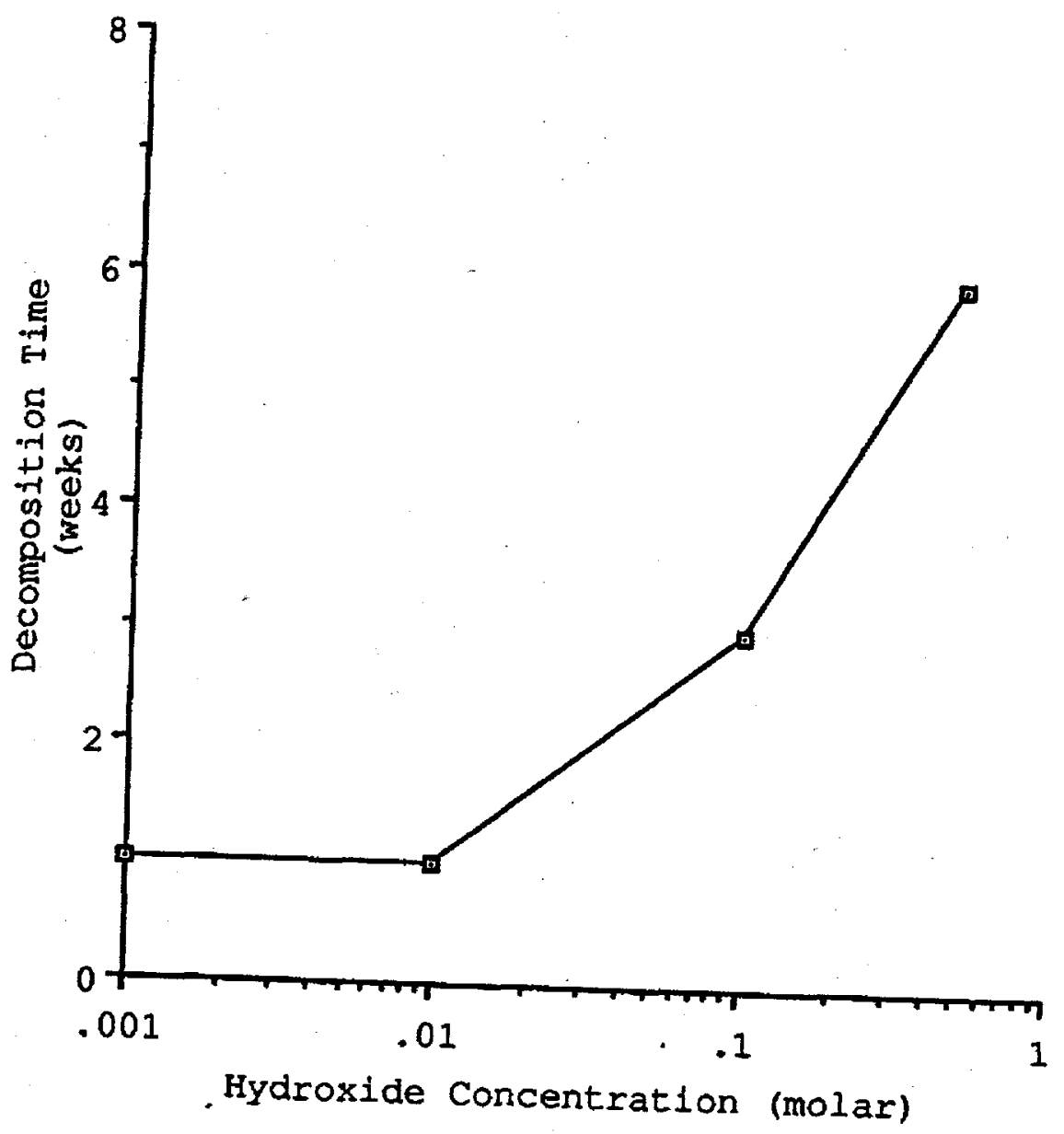


cc: W. I. Tamosaitis, 773-A

D. D. Walker, 773-A

D. T. Hobbe, 773-A

R. G. Garvin, 703-H

H. L. Martin, 703-H

W. B. Van Pelt, 241-121H

N. R. Davis, 241-120H

D. E. Bryson-Lewis, 320-M

A. 0. Delley, 703-H

W. E. Phillips, 241-121H

E. W. Manci, 703-H

T. A. Grzech, 703-H 


\section{Appondix $\mathbf{A}$ \\ Preliminary ixperiments on Sodium retraphenylborate stability}

Preliminary experiments on the stability of 0.5 molar sodium tetraphenyiborate solutions were performed by $D$. $D$. Walker and recorded in laboratory notebook DPSTN-4749, pp 88-97, and WSRC-NB89-148, pp 4-9. The experimental procedure was similar to that reported here. All solutions contained $0.10( \pm .01)$ molar free $\mathrm{NaOH}$ and 0.50 ( \pm .03 ) molar sodium tetraphenylborate initially. The sodium tetraphenylborate was high purity $(99+8)$ reagent grade. The metal salts used were all nitrates. Solutions (25 $\mathrm{mL})$ were placed in capped polyethylene bottles $(50 \mathrm{~mL})$ under air and stored in an incubator at $65^{\circ} \mathrm{C}\left( \pm 1^{\circ} \mathrm{C}\right)$. Each week for eight weeks the samples were removed from the incubator, cooled to room temperature, and a portion removed for analysis.

Table A-1 lists the results of these tests. Within the ranges tested, only one component, Cu(II), appeared to cause decomposition within eight weeks. The samples with 10, 30, and $100 \mathrm{ppm} \mathrm{Cu}$ were repeated and the time required for decomposition to occur was found to vary by several weeks. The last three samples listed, which had a portion of already-decomposed solution added to them, contained $C u$ (II) in very small amounts. The estimated copper contents are shown. 
Table $\mathrm{A}-1$

Results of Preliminary Experiments

Yariable

polyethylene

glass

Nitrate ion

$\operatorname{Zn}(I I)$

$\operatorname{Cr}(I I)$

$\mathrm{Hg}(I I)$

$\mathrm{Cu}\langle I I\rangle$

phenol

$500,1500,3000$ ppm

sodium

phenylborat $500,1500,3000$ ppm

Sodium tetraborate (borax)

$$
500,1500,3000 \text { ppm }
$$

Hydrogen peroxide

$$
1200,3600,12000 \mathrm{ppm}
$$

Decomposed NaTPB solution

$$
\text { 4,000 ppm }
$$
$20,000 \mathrm{ppm}$

(0.04 ppm Cu)

$(0.2 \mathrm{ppm} \mathrm{Cu})$ $60,000 \mathrm{ppm}$ no decomposition

\section{obserrations}

no decomposition

no decomposition

no decomposition

no decomposition

no decomposition

no decomposition

decomposed in $<1$ week decomposed in 1-7 weeks decomposed in $2-8$ weeks

no decomposition

disodium salt)

no decomposition

no decomposition

no decomposition

decomposed in 7-8 weeks decomposed slowly in 1-4 weeks 